\title{
Multi-Center Study on the Prevalence of Human Immunodeficiency Virus/Herpes Simplex Virus Type-2 Co-Infection among Pregnant Women in Nigeria
}

\section{Olayemi MATTHEW ${ }^{1,2^{*}}$, Teclaire NDOMB ${ }^{1,3}$, Joseph ONAKEWHOR ${ }^{4}$, Bitrus MATAWAL ${ }^{5}$, Esosa OSAGIE ${ }^{1,4}$, Alashle ABIMIKU ${ }^{1,3,6}$ and Man CHARURAT}

\author{
${ }^{1}$ Institute of Human Virology Nigeria, Nigeria \\ ${ }^{2}$ California Miramar University, USA \\ ${ }^{3}$ Plateau Laboratory Virology Research Center, Nigeria \\ ${ }^{4}$ University of Benin Teaching Hospital, Nigeria \\ ${ }^{5}$ Plateau State Specialist Hospital, Nigeria
}

${ }^{6}$ Institute of Human Virology, University of Maryland School of Medicine, USA

*Corresponding author: Olayemi Matthew, Institute of Human Virology Nigeria, Abuja, Nigeria; California Miramar University, 3550 Camino Del Rio North, Ste 208. San Diego, CA 92108, USA, Tel: +1-443-712-3288, ORCID ID: 0000-00031117-1916

\begin{abstract}
Objectives: Substantial proportions of new HIV infections in sub-Saharan Africa are associated with herpes simplex virus type 2 (HSV-2) infection hence the magnitude of infection in the population suggests the expected course of HIV epidemic. We determined prevalence of genital herpes as a result of HSV-2 and its associated factors among pregnant women in Nigeria.

Methods: A total of 2,362 sera of pregnant women aged 18-49 years attending two different antenatal clinics in two communities in Nigeria were analysed using ELISA specific for IgG antibodies to HSV-2 (Kalon Biological Ltd, U.K). HIV antibodies were screened using sequential algorithm of rapid HIV tests.

Results: Prevalence of genital herpes was 38.8\% (95\% Cl: $36.8-40.7 \%)$. HSV-2 was associated with first time pregnancy, high maternal age and age of sex partner in this study. 264 women (11.2\%) had current symptomatic genital ulceration. Odds of HSV-2 sero-positivity was 6 times higher in HIV-sero-positive than sero-negative women $(76.3 \%$ vs. $34.9 \%, p<0.001)$. This remained significant after controlling for age, education, marital status and religion. Among HIV-sero-positive women, low CD4 and current genital ulcerative disease (GUD) were associated with higher HSV2 prevalence.
\end{abstract}

Conclusion: HSV-2 was highly prevalent; few women had prior or current GUD. Treatment of HSV-2 in populations like pregnant women would be among approaches towards preventing and managing HIV infections.

\section{Keywords}

Herpes simplex virus type 2 (HSV-2), Human immunodeficiency virus (HIV), Pregnant women, Sexually transmitted infections (STI), Co-infection, Nigeria

\section{Introduction}

Herpes Simplex Virus type 2 (HSV-2) infection is a sexually transmitted infection (STI) which is recognized as the most common cause of genital ulcer disease worldwide [1,2].

Most of the people infected are unaware in spite of symptoms [3]. HSV-2 infection is a growing global problem with high prevalence in women in developing countries, especially those with human immunodeficiency virus (HIV) infection [4]. Studies show that STIs like HSV-2 increases the probability of someone acquiring HIV as well as enhances transmission by increasing susceptibility and infectiousness [5]. Herpes 
infection affects the genital mucosa causing increased multiplication of virus and high transmission rate in an HIV seropositive person [6]. The risk of contracting HIV is higher with acute HSV-2 than chronic ones and most people infected are unaware despite the symptoms [7].

Studies in the African continent have shown variation in HSV-2 prevalence across diverse populations of women, ranging from $22 \%$ among adults in Tanzania and $68 \%$ among adults in urban Kenya to $90 \%$ among commercial sex workers in Zaire [8]. In Western Kenya, an HIV survey among women aged 13-34 years conducted in 2003-2004 revealed an HSV-2 prevalence of 53\% [9]. A more recent National AIDS Indicator survey among general population of women aged 15-64 years in Kenya estimated HSV- 2 prevalence to be $42 \%$ [9]. Mbizvo, et al. in their study also estimated $42.2 \%$ among women of child bearing age in Zimbabwe [10]. The first documented isolation of HSV-2 in Nigeria was done in Ibadan at the STD clinic of the University College Hospital in 1992 where prevalence was determined to be $3.27 \%$ [11]. The HSV-2 sero-prevalence among female sex workers in Lagos, Nigeria, was 59\% [12].

HSV-2 is implicated as co-factor in HIV acquisition and transmission, which may contribute greatly to HIV infections by facilitating its spread among the low-risk population within a stable sexual relationship [13]. A study conducted in four cities of Africa revealed that among two West African cities with low HSV-2 prevalence, HIV was observed to be constant in the highrisk group of individuals [13]. However, among cities with high herpes simplex prevalence, HIV transmission was observed in a larger fraction of the population [14]. These results suggest that HSV-2 may be the cause of the massive spread of HIV and also corroborated by the epidemiological symbiosis of HIV and HSV-2 [14]. The increasing evidence that HSV-2 facilitates HIV acquisition and spread and the symbiotic effect of HSV2 on HIV, makes the development of control measures for HSV-2 a priority [13-15].

Pregnancy is an evidence of unprotected sexual intercourse; hence pregnant women are the most appropriate target population for studying and identifying factors regarding sexual behaviour and STIs. Some women acquire HSV-2 infection during pregnancy, where the infection is acquired close to term there is a high risk of transmitting the virus from the lower genitalia to the baby during vaginal delivery. Complications from disseminated disease and visceral organ involvement in neonates are becoming less severe with the use of antiviral therapy. Encephalitis is usually a common aspect of these disseminated disease as well as the presence of a vesicular rash. Death which rarely occurs is in connection to severe coagulopathy, liver dysfunction, and pulmonary involvement of the disease [15-18].

\section{Objectives}

The main objective of our study was to determine the prevalence of genital herpes and its associated factors among pregnant women in two communities in Nigeria that have a low but increasing HIV prevalence. Since more than $75 \%$ of primary genital herpes virus infections are asymptomatic [16], epidemiological studies are important in understanding the pattern and distribution of infection within the population to appreciate the HSV2 related HIV transmission dynamic [19].

\section{Methods}

\section{Study area and population}

This was a cross-sectional analysis of a cohort study which was conducted in two states of Nigeria, Plateau State in the North-Central region and Edo State in the South-South region, to characterize HIV and non-HIV STI epidemiology and their risk factors with an aim focused towards prevention. Between April 2010 and July 2011, a total of 2362 pregnant women between 18 and 49 years regardless of gestational age period attending antenatal clinics (ANC) at the Plateau State Specialist Hospital and the University of Benin Teaching Hospital were enrolled into the study after giving written informed consent to participate. All of them had their sera tested for HIV and HSV-2. The study protocol was approved by the University of Maryland Baltimore Institutional Review Board and the ethics review committees at the local hospitals.

\section{Data collection}

A standard structured questionnaire was administered to all participants. At baseline, information on socio- demographic characteristics like age, religion, educational qualification etc were obtained. Obstetric history like date of last menstrual period and previous obstetric history were obtained. Other clinical history and signs and symptoms associated with genito-pelvic infections were obtained from all the participants at the antenatal clinic both at baseline and all subsequent follow-up visits. Pre and post-test HIV counselling were provided to all the participants.

\section{Specimen collection and laboratory tests}

Blood specimen was collected in two vacutainer tubes (4 mL EDTA, $4 \mathrm{~mL}$ plain tube). An aliquot of the Plasma was used for the HIV testing at enrolment visit. This was done using Sequential Rapid test kits: DETERMINE ${ }^{(R)}$ Abbot Laboratories, 100 Abbot Park, IL 60064 United States, UNIGOLD ${ }^{(R)}$ - Trinity Biotech Plc, Bray, Ireland. In cases of serial discrepant Rapid HIV Test Results, these results were resolved using a Tie-Breaker STATPAK ${ }^{(R)}$ Chembio diagnostics Systems, Inc. Medford, N.Y. 11763 USA. All the HIV negative plasma samples were stored immediately at $-80^{\circ} \mathrm{C}$ and later pooled for the detection of HIV RNA using ROCHE- TAQMAN system ${ }^{(R)}$ - Roche 
diagnostics Corporation 9115 Hague Road, Indianapolis, Indiana 46250 USA.

The women that were confirmed HIV positive were called back during their next antenatal care visit and had their blood drawn for CD4 cells count. This was measured with a Flow cytometer ${ }^{(R)}$ - Partec Inc, 603 Heron Drive unit 9, Swedesborg, NJ 08085 USA.

For the HSV-2, serum was stored at $-80{ }^{\circ} \mathrm{C}$. The stored serum samples from the date of enrolment were identified for the cohort study, approximately 10ul of this stored serum was used for the HSV-2 testing. The remaining sample was stored back in the $-80{ }^{\circ} \mathrm{C}$ freezer for further testing.

Each woman's HSV-2 status was defined by detection of HSV-2 specific antibodies using KALON HSV-2 IgG $E$ LISA $^{(R)}$ - Kalon Biological Ltd, Guildford, Surrey GUH 7BN - United Kingdom. This assay showed a sensitivity ranging from $92.3 \%$ to $97.7 \%$ in large studies of sera from Kenya, Zambia, Benin and 85\% Specificity [20]. According to the protocol, a Positive Predictive value is $92 \%$ while a Negative Predictive value is $97 \%$. Sera with optical density less than 0.9 were considered negative and those with optical density greater than 1.1 were positive. Results between these values, that were between 0.9 - 1.1 were equivocal and were repeat tested to confirm status. Of the total 2362 samples analysed, $22(0.9 \%)$ were with indeterminate HSV-2 serology results hence were excluded from the analysis.

\section{Statistical analyses}

Analysis of data was done using SAS software version 9.2. HSV-2 sero-prevalence was calculated for the 2362 women. Difference in mean was measured using T-test. Logistic regression was used to compute univariate and stratified odds ratios (OR) and $95 \% \mathrm{Cl}$ for demographic, sexual, clinical, and serological variables associated with HSV-2 sero-positivity. Chi-square and Fisher's exact test were used to test for statistically significant associations. Multivariate logistic regression was used to determine the independence and adjusted $O R\left(O R_{\text {adj }}\right)$ of variables associated with HSV-2. Variables with $P<0.10$ were retained in the multivariate model. Confounding by variables were evaluated by stratification and magnitude of the change in estimate. All statistical tests were two-sided.

\section{Results}

\section{Sero-prevalence}

The mean age of the study population was 29.0 years; over one-third (36.0\%) of women fall within this age group. The prevalence of HSV-2 sero-positivity was $38.8 \%$ (95Cl: $36.8 \%-40.7 \%$ ). Majority of the women in our study population $(96.8 \%)$ had one sex partner within the last 3 months. Ninety five percent (95\%) of the women do not use condoms weekly. About twenty percent $(19.6 \%)$ of the women were pregnant for the first time (Table 1).

The prevalence of HSV-2 sero-positivity gradually significantly rose with increase in maternal age. HSV-2 sero-prevalence was also higher among women who were booked and enrolled in the study before 18 weeks gestation compared to women booked and enrolled at 32 weeks gestation and above $(41.4 \%$ vs. $33.1 \%, P$ $=0.06$ ). The prevalence of HSV-2 did not vary with douching practices. The prevalence of genital ulcerative disease (GUD) was $18.2 \%$, while the prevalence of HSV2 among those with GUD was $61.9 \%$ compared to $33.6 \%$ without GUD $(P<0.001)$ (Table 1$)$.

Table 1: Risk factors for HSV-2 sero-positivity-All women.

\begin{tabular}{|l|l|l|l|l|}
\hline Risk Factors & Total & $\begin{array}{l}\text { No. of } \\
\text { HSV-2 Pos. } \\
\text { women }\end{array}$ & $\begin{array}{l}\text { HSV-2 } \\
\text { Pos \% }\end{array}$ & P-value \\
\hline Age (years) & \multicolumn{4}{|l|}{} \\
\hline $18-24$ & 416 & 97 & $23.30 \%$ & \\
\hline $25-29$ & 905 & 326 & $36.00 \%$ & \multirow{2}{*}{$<0.0001$} \\
\hline $30-34$ & 678 & 312 & $46.00 \%$ & \\
\hline $35+$ & 340 & 172 & $50.60 \%$ & \\
\hline
\end{tabular}

\section{Gest. Age (weeks)}

\begin{tabular}{|l|l|l|l|l|}
\hline $0-18$ & 926 & 383 & $41.40 \%$ & \\
\hline $19-31$ & 1250 & 470 & $37.60 \%$ & 0.0632 \\
\hline $32+$ & 163 & 54 & $33.10 \%$ & \\
\hline
\end{tabular}

No. of sex partners (past 3 months)

\begin{tabular}{|c|c|c|c|c|}
\hline 0 & 74 & 42 & $56.80 \%$ & \multirow{4}{*}{0.005} \\
\hline 1 & 2262 & 864 & $38.20 \%$ & \\
\hline 2 & 1 & 1 & $100 \%$ & \\
\hline 3 & 1 & 0 & 0 & \\
\hline
\end{tabular}

\begin{tabular}{|l|l|l|l|l|}
\hline Douching & \multicolumn{5}{|l|}{$\mid$} \\
\hline No & 625 & 235 & $37.60 \%$ & 0.47 \\
\hline Yes & 1713 & 672 & $39.20 \%$ & \\
\hline Condom freq. (weekly) & & $37.80 \%$ & \\
\hline 0 & 2233 & 843 & $60.00 \%$ & $<0.0001$ \\
\hline $1-2$ & 70 & 42 & $62.90 \%$ & \\
\hline $3+$ & 35 & 22 & & \\
\hline
\end{tabular}

\section{Genital ulcer disease}

\begin{tabular}{|l|l|l|l|l|}
\hline No & 1914 & 644 & $33.60 \%$ & \multirow{2}{*}{$<0.001$} \\
\hline Yes & 426 & 264 & $61.90 \%$ & \\
\cline { 1 - 5 } & & &
\end{tabular}

Age of sex partner (years)

\begin{tabular}{|l|l|l|l|l|}
\hline $18-24$ & 25 & 2 & $8.00 \%$ & \\
\hline $25-29$ & 230 & 47 & $20.40 \%$ & \\
\hline $30-34$ & 667 & 223 & $33.40 \%$ & $<0.0001$ \\
\hline $35+$ & 1307 & 587 & $44.90 \%$ & \\
\hline
\end{tabular}

\begin{tabular}{|l|l|l|l|l|}
\hline First pregnancy & \multicolumn{5}{|l|}{$\mid$} \\
\hline No & 1880 & 800 & $42.60 \%$ & $<0.0001$ \\
\hline Yes & 458 & 106 & $23.10 \%$ & \\
\hline
\end{tabular}

\section{HIV status}

\begin{tabular}{|l|l|l|l|l|}
\hline Negative & 1924 & 672 & $34.90 \%$ & \multirow{2}{*}{0.0001} \\
\hline Positive & 224 & 171 & $76.30 \%$ & \\
\hline
\end{tabular}


Table 2: Multivariate analysis of risk factors -All women.

\begin{tabular}{|l|l|l|}
\hline Risk Factors & $\begin{array}{l}\text { Odds Ratios } \\
\text { (95\% Confidence } \\
\text { Intervals) }\end{array}$ & $\boldsymbol{P}$ value \\
\hline Age (per 5 years increase) & $1.4(1.1-2.1)$ & 0.03 \\
\hline $\begin{array}{l}\text { Age of sex partner (per 5 } \\
\text { years increase) }\end{array}$ & $1.5(1.0-2.2)$ & 0.04 \\
\hline HIV sero-positivity & $6.0(4.3-8.3)$ & $<0.001$ \\
\hline Not first pregnancy & $1.9(1.5-2.2)$ & $<0.001$ \\
\hline Current or prior GUD & $2.4(1.9-3.4)$ & $<0.001$ \\
\hline
\end{tabular}

Of the 2362 women tested, 224 were HIV seropositive resulting in HIV sero-prevalence of $13.9 \%$. The prevalence of HSV-2 among those who are HIV+ was 76.3\% compared to $34.9 \%$ for HIV- mothers $(P<0.001)$ (Table 1).

\section{Risk factors}

Close to two - third (60.2\%) of the women's sexual partner are over 35 years of age, having an older partner has a strong association with sero-positivity of HSV-2 ( $P$ $<0.0001$ ).

With multivariate analysis, there was a significant association between HSV-2 Sero-positivity with maternal age, age of sex partners, first pregnancy and HIV status. With every 5 years increase in age of the mothers, the risk for HSV-2 went up by 1.4-fold, while with every 5 years increase in age of the partner the risk increased by 1.5 -fold (Table 2 and Table 3 ).

The median CD4+ lymphocyte count for women at booking and study enrolment was 385 cells per $\mathrm{ml}$ (interquartile range: $256-529$ cells $/ \mathrm{ml}$. There was also a trend for high mean HIV-1 copies/ml of viral loads among HSV-2 seropositive women (4.08 log10 copies/ $\mathrm{ml}$ vs. $3.94 \log 10$ copies $/ \mathrm{ml}$ ). $87 \%$ of the HIV+ women were on antiretroviral therapy (ART) at the time of booking and $100 \%$ were subsequently placed on antiretroviral (ARV) prophylaxis for the prevention of mother-to-child transmission (PMTCT). These ART are comprised of triple ARV such as ZDV -3TC-EFV with ZVD -3TC-NVP being the most common regimen (70.9\%). There is a strong interaction between GUD, HSV-2, and CD4 (Figure 1). HSV-2 sero-prevalence was $92.3 \%$ for women with CD4 $<200$ and presented with GUD compared to $71.6 \%$ for women in the same CD4 strata but did not have GUD $(P<0.001)$. Similar associations were observed for women with CD4 between 200 and 350 cells $/ \mathrm{ml}$ and women with CD4 above 350 cells $/ \mathrm{ml}$. Women in the highest CD4 strata without GUD had the lowest HSV-2 prevalence (Figure 1). Douching practices had no statistically significant effects on the risk of acquiring HSV-2.

\section{Discussion}

The prevalence of HSV-2 sero-positivity in this study was $38.8 \%$, similar results were obtained in Tanzania
Table 3: Risk factors for HSV2 sero-positivity - HIV seropositive women only.

\begin{tabular}{|c|c|c|c|c|}
\hline Risk Factors & Total & $\begin{array}{l}\text { No. of } \\
\text { HSV-2 Pos. } \\
\text { women }\end{array}$ & $\begin{array}{l}\text { HSV-2 } \\
\text { Pos\% }\end{array}$ & $P$-value \\
\hline \multicolumn{5}{|l|}{ Age (years) } \\
\hline $18-24$ & 15 & 9 & $60.00 \%$ & \multirow{4}{*}{0.0772} \\
\hline $25-29$ & 92 & 66 & $71.70 \%$ & \\
\hline $30-34$ & 81 & 69 & $85.20 \%$ & \\
\hline $35+$ & 36 & 27 & $75.00 \%$ & \\
\hline \multicolumn{5}{|c|}{ Gest. Age (weeks) } \\
\hline $0-18$ & 110 & 84 & $76.40 \%$ & \multirow{3}{*}{0.834} \\
\hline $19-31$ & 97 & 75 & $77.30 \%$ & \\
\hline $32+$ & 17 & 12 & $70.60 \%$ & \\
\hline \multicolumn{5}{|c|}{ No. of sex partners (past 3 months) } \\
\hline 1 & 19 & 18 & $94.70 \%$ & \multirow{2}{*}{0.0486} \\
\hline 1 & 205 & 153 & $74.60 \%$ & \\
\hline \multicolumn{5}{|l|}{ Douching } \\
\hline No & 89 & 70 & $78.70 \%$ & \multirow{2}{*}{0.5085} \\
\hline Yes & 135 & 101 & $74.28 \%$ & \\
\hline \multicolumn{5}{|c|}{ Condom freq. (weekly) } \\
\hline 0 & 155 & 122 & $78.70 \%$ & \multirow{3}{*}{0.4454} \\
\hline 2-Jan & 47 & 33 & $70.20 \%$ & \\
\hline $3+$ & 22 & 16 & $72.70 \%$ & \\
\hline \multicolumn{5}{|c|}{ Genital ulcer disease } \\
\hline No & 220 & 168 & $76.40 \%$ & \multirow{2}{*}{0.9494} \\
\hline Yes & 4 & 3 & $75.00 \%$ & \\
\hline
\end{tabular}

Age of sex partner (years)

\begin{tabular}{|l|l|l|l|l|}
\hline $25-29$ & 8 & 5 & $62.50 \%$ & \\
\hline $30-34$ & 46 & 30 & $65.20 \%$ & 0.1363 \\
\hline $35+$ & 149 & 117 & $78.50 \%$ & \\
\hline First pregnancy & \multicolumn{5}{|l|}{} \\
\hline No & 192 & 146 & $76.00 \%$ & \multirow{2}{*}{0.7974} \\
\hline Yes & 32 & 25 & $78.10 \%$ & \\
\hline
\end{tabular}

with a prevalence of $39 \%$ found in the general population [21]. Studies from rural areas in Zambia in West Africa have shown infection rate of $30 \%$ among women [20]. The work of Mujoma, in 2010 in Zimbabwe, reported a prevalence of HSV-2 of $49.1 \%$ among pregnant women [22]. Another study conducted in four African cities revealed that in two West African cities with lower HSV-2 prevalence, HIV remained concentrated in higher risk groups. But, in the cities with high HSV-2 prevalence, HIV was observed in a large fraction of the population [20].

Predisposing factors like age has been shown to be associated with the acquisition of the HVS-2 virus $[23,24]$, in our study those above 35 years of age had the highest prevalence for sero-positivity, which is similar to what was reported in the Kenyan AIDS indicator survey [9]. Glynn, et al., Simon, et al. and UNAIDS also recorded strong association between HSV-2 sero-prevalence and 


\section{HSV-2 Seropositive (\%)}

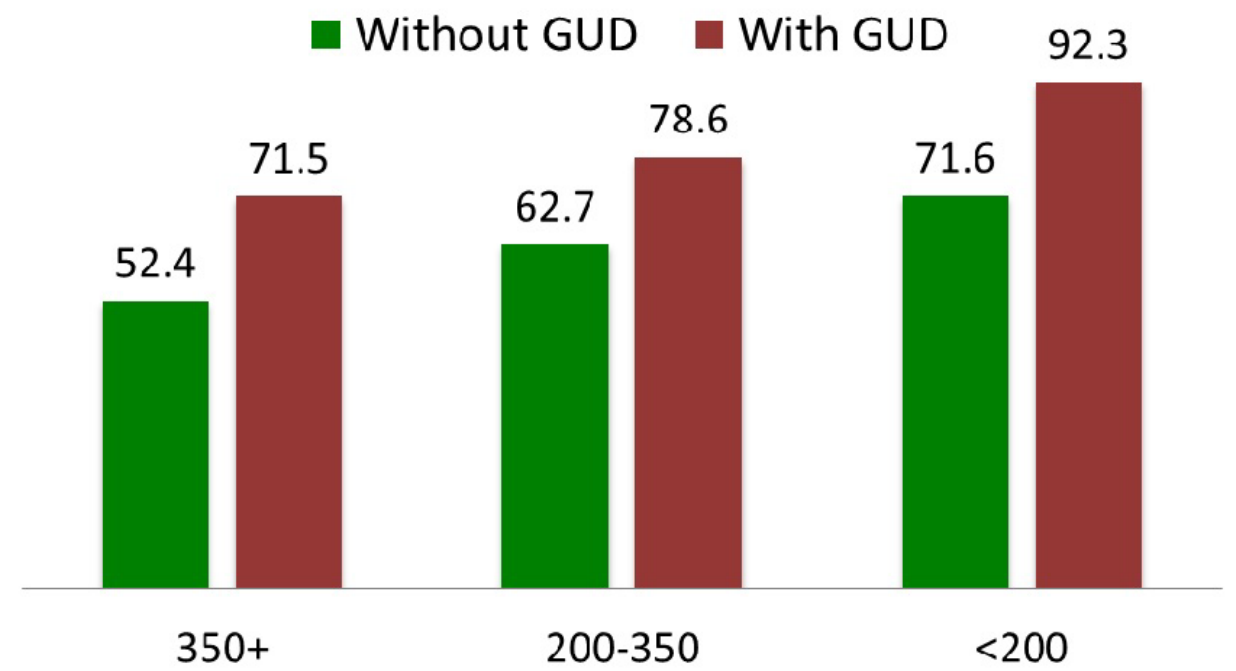

Figure 1: HSV2 sero-positivity at CD4 cells counts among HIV positive women with GUD.

age $[20,25,26]$. The trend of a higher prevalence of HSV2 infection with increasing age is substantiated by similar reports from Lagos, Nigeria [12] and Sweden [21] which also suggested that increasing partner age was a possible risk factor for HSV-2 infection. Also, HSV-2 infection is a lifelong infection with a high rate of transmission [27]. This is because age difference between women and their husbands remained a silent driver of the HIV epidemic as the older men have more exposure than the young women resulting in disproportionate prevalence of STI between men and women.

From our study, the HIV sero-positivity is $13.9 \%$ meanwhile the HSV-2 prevalence among HIV positive is 76.3\%. This was also reported in Zimbabwe by Mbizvo [10] and Anna Wald [17] who showed that HSV-2 seropositive women were about three times more likely to be HIV positive than HSV-2 negative women. A similar finding was shown by Eis-Hubinger, et al. [28] in Cameroun where the sero-prevalence of HSV-2 in HIV infected pregnant women was $70 \%$. In Mulango Uganda the proportion of HSV-2 among HIV positive and HIV negative pregnant women were $86 \%$ \& $62 \%$ respectively [24]. The disparities in HSV-2 prevalence between HIV positive and negative individuals indicate an increase susceptibility of the HSV-2 sero-positivity to HIV Infection. Meanwhile Positive HIV status was the strongest independent predictor of HSV-2 seropositivity as similarly reported in other studies $[17,28]$. HIV infection increases the risk of acquisition of HSV-2, the frequency and severity and reactivation $[29,30]$. In resource limited settings with high HIV prevalence such as the Central African Republic, HSV-2 antibody prevalence among HIV infected is $91 \%$. The presence of HSV-2 infection indicates a potential mechanism for future HIV transmission [31,32]. Thus, there appear to be true epidemiologic synergy between those two viruses in that HIV incidence is increased in parallel with HSV-2 among HIV negative and Positive person and HIV prevalence increases HSV-2 incidence [31]. Because of the Synergy between the two viruses, it follows that HIV infected/ HSV-2 uninfected people are also at risk of acquiring HSV-2 [32]. If these women acquire HSV2 infection late in pregnancy their risk of transmitting the virus to infant intra-partum is high [33]. The low prevalence of HSV-2 in our study compare to other African studies can be justified by the widespread public awareness in Nigeria in the last few years on practice of safe sex to fight the HIV epidemic in the country.

The general GUD prevalence in this study was $18.2 \%$, but in the HIV sero-positive women, the prevalence of GUD was $52 \%$, this is lower to the study in Kenya, where a prevalence of HSV-2 with GUD was $10 \%$ [34]. In that study, the frequency of genital ulcer disease consistent with reactivation of HSV-2 was found to increase in a stepwise fashion with a declining CD4 count [34]. In our study, 38\% of women with GUD and HSV-2/HIV have lower CD4 cells count $(<350$ cell $/ \mathrm{ml})$. This is similar to Roxby, et al. [35] who showed that women with GUD and HSV-2 have lower CD4 counts compared to women with just HSV-2 alone, he indicated that $8 \%$ of HSV-2 seropositive women with GUD were more likely to have CD4 count $\leq 200$ cells $/ \mathrm{ml}$ at baseline. In a similar study done in Surat and Delhi it was also observed that higher HSV-2 sero-prevalence in subjects with GUD, vaginal discharge and low backache [1]. The risk factors for HSV2 are well known and include polygamous relationships/ multiple sex partners, unsafe sex, increasing numbers of lifetime partners and association with other STI's or GUD etc. [36]. Most women in our study (96.8\%) had one sexual partner. In Dipankar Biswas study, it was shown that subjects with multiple sex partners had significantly higher HSV-2 sero-prevalence compared to 
single sex partner [37]. GUD increases the risk of HIV transmission among HIV infected persons [38].

\section{Limitations}

Limitations in our analysis include the challenges of identifying prior GUD, due to symptoms of varying severity. Women many not have recalled prior GUD at study entry. As this was a cross-sectional design, incident ulcers were not systematically assessed, therefore were not included in our analysis. Nonetheless, our results highlights the potential public health impact of HSV-2 in Nigeria where HSV-2 testing is not performed routinely for ANC attendees considering the risk of neonatal transmission and the attendant complications at birth as well as the synergy between HIV and HSV-2 transmission.

\section{Conclusion}

In conclusion, pregnant women are at a greater risk of HIV if they had no evidence of past HSV-2 infection [17]. Women infected with HSV-2 have greater risk of acquiring HIV, and HSV-2 infection may remain a driving force behind the HIV epidemic in this research. It has been shown that the rate of reactivation of HSV-2 in labour was found to be $63.6 \%$ in women of unknown HIV sero-status [38]. Therefore, there is urgent need to recognise HSV-2 infection among the population at risk, especially identification of new HSV-2 infection in pregnancy may indirectly impact on mother-to-child transmission of HIV, especially in Africa where HSV2 infection affects most HIV Sero-positive pregnant women [22]. Over $70 \%$ of infected pregnant women were seropositive for HSV-2 and were more likely to have Herpes reactivation in pregnancy [33]. All HIV positive women had ARV prophylaxis which was highly effective. Priority should be given to the development of Rapid HSV-2 specific tests. The use of the Kalon ELISA also strengthens our diagnosis as others have shown that it had a higher specificity on clinic-virological panel than the Herpes Simplex ELISA, a commonly used assay [18]. The diagnosis and management of genital herpes presents a challenge for public health programmes and for clinicians in developing countries, therefore the approach needed may differ between areas depending on the stage of HIV epidemic, the prevalence HSV-2 in high risk population, and the cost and availability of diagnostic tests and treatment. In conclusion, there is also need to integrate HSV-2 and HIV prevention efforts to the country at risk of increasing HIV infection.

\section{Acknowledgement}

This work was supported by funding from the U.S. $\mathrm{NIH} \mathrm{R01AI074594}$ and the University of Maryland Institute of Human Virology AIDS International Training Research Program D43TW001041.

We declare no conflict of interest; there was no undue influence to the objectivity of this paper. The authors alone are responsible for the content and writing of the paper.

We have the Ethics and Research Committee's approval for the study.

\section{References}

1. Chris Beyrer, Kriangsak Jitwacharanan, Chawalit Natpratan, Rassamee Kaewvichit, Kendrad E Nelson, et al. (1998) Molecular methods for the diagnosis of genital ulcer disease in sexually transmitted disease clinic population in northern Thailand: Predominance of herpes simplex virus infection. J Infect Dis 178: 243-246.

2. Chen Cheng $Y$, Ballard Ronald $C$, Beck-Sague Consuelo M, Yusuf Dangor, Frans Radebe, et al. (2000) Human immunodeficiency virus infection and genital ulcer disease in South- Africa: The herpetic connection. Sex Transm Dis 27: 21-29.

3. Brugha R, Keersmaekers K, Renton A, Meheus A (1997) Genital herpes infection: A review. Int J Epidemiol 26: 698709.

4. Yusuf A Agabi, Edmund B Banwat, John D Mawak, Patricia M Lar, Nanma Dashe, et al. (2010) Seroprevalence of herpes simplex virus type-2 among patients attending the Sexually Transmitted Infections Clinic in Jos, Nigeria. J Infect Dev Ctries 4: 572-575.

5. Serwadda D, Gray RH, Sewankambo NK, Wabwire-Mangen F, Chen MZ, et al. (2003) HIV acquisition associated with genital ulcer disease and HIV 2 Infection: A nested casecontrol study in Rakai, Uganda. J Infect Dis 188: 14921497.

6. Ghys PD, Fransen K, Diallo MO, Ettiegne-Traore V, Coulibaly IM, et al. (1997) The associations between cervico-vaginal HIV shedding, sexually transmitted diseases and immunosuppression in female sex workers in Abidjan, Cote-d'ivoire. AIDS 11: 85-93.

7. Maria del Mar Rodriguez Pujades, Angela Obasi, Frank Mosha, Jim Todd, David Brown, et al. (2002) Herpes simplex virus type 2 infection increases HIV incidence: A prospective study in rural Tanzania. AIDS 16: 451-462.

8. Amornkul N Pauli, Vandenhoudt Hilde, Nasokho Peter, Odhiambo Frank, Mwaengo Dufton, et al. (2009) HIV prevalence and associated risk factors among individuals aged 13-34 years in rural western kenya. PLoS One 4: e6470.

9. National AIDS and STI Control Programme (2009) 2007 Kenya AIDS Indicator Survey, Official KAIS report.

10. Mbizvo EM, Msuya SE, Stray-Pedersen B, Chirenje MZ, Munjoma M, et al. (2002) Association of herpes simplex virus type 2 with human immunodeficiency virus among urban women in Zimbabwe. Int J STD AIDS 13: 343-348.

11. Oni AA, Adu FD, Ekweozor CC (1994) Isolation of herpes simplex virus from sexually transmitted disease patients in Ibadan Nigeria. Sex Transm Dis 21: 187-190.

12. Dada AJ, Ajayi AO, Diamondstone L, Quinn TC, Blattner WA, et al. (1998) A serosurvey of haemophilus ducreyi, syphilis, and herpes simplex virus type-2 and their association with HIV among workers in Lagos, Nigeria. Sex Transm Dis 25: 237-242.

13. Laith J Abu-Raddad, Amalia S Magaret, Connie Celum, Anna Wald, Ira M Longini Jr, et al. (2008) Genital herpes has played a more important role than any other sexually transmitted infection in driving HIV prevalence in Africa. PLoS ONE 3: e2230. 
14. Augenbraun M, Feldman J, Chirgwin K, Zenilman J, Clarke L, et al. (1995) Increased genital shedding of HSV-2 in HIV seropositive women. Ann Intern Med 123: 845-847.

15. Buve A, Carael M, Hayes RJ, Auvert B, Ferry B, et al (2001) The multicentre study on factors determining the differential spread of HIV in four African cities: Summary and conclusions. AIDS 4: S127-S131.

16. Weiss HA, Buve A, Robinson NJ, Van Dyck E, Kahindo $M$, et al. (2001) The epidemiology of HSV-2 infection and its association with HIV infection in four urban African populations. AIDS 4: S97-S108.

17. Anna Wald, Katrine Link (2002) Risk of human immunodeficiency virus infection in herpes simplex virus type 2 seropositive persons: A meta-analysis. J Infect Dis 185: 45-52.

18. Pickering JM, Whitworth JA, Hughes $P$, Kasse M, Morgan D, et al. (2005) Aetiology of sexually transmitted infections and response to syndromic treatment in southwest Uganda. Sex Transm Infect 81: 488-493.

19. http://emedicine.medscape.com/article/274874-overview

20. Glynn JR, Carael M, Auvert B, Kahindo M, Chege J, et al. (2001) Why do young women have a much higher prevalence of HIV than young men? A study in Kisumu, Kenya and Ndola, Zambia. AIDS 15: S51-S60.

21. Msuya SE, Hussein A, Sam NE, Jeansson S, Stray PB, et al. (2003) Seroprevalence and correlates of HSV-2 among urban Tanzanian women. Sex Transm Dis 30: 588-592.

22. Marshall W Munjoma, Edith $N$ Kurewa, Munyaradzi $P$ Mapingure, Grace V Mashavave, Mike Z Chirenje, et al. (2010) The Prevalence, incidence and risk factors of herpes simplex virus type 2 , infection among pregnant Zimbabwean women followed up nine month after childbirth. BMC Womens Health 10: 2.

23. Christenson B, Bottiger M, Svensson A, Jeansson S (2002) A 15 year surveillance study of antibody to Herpes simplex virus $1 \& 2$ in a cohort of young girls. J Infect 25: 147-154.

24. Sarah Nakubulwa, Florence M Mirembe, Dan K Kaye, Deogratias Kaddu-Mulindwa (2009) Association between HSV-2 and HIV serostatus in pregnant women of known HIV serostatus attending Mulago hospital antenatal clinic, Kampala, Uganda. J Infect Dev Ctries 3: 803-806.

25. UNIAIDS (2013) Report on the global AIDS epidemic.

26. Simon Gregson, Nyamukapa Constance A, Garnett Geoffret P, Mason Peter R, Tom Zhuwau, et al. (2002) Sexual mixing patterns and sexual-differentials in teenage exposure to HIV infection in rural Zimbabwe. Lancet 359: 1896-1903.
27. Weiss H (2004) Epidemiology of herpes simplex virus type2 infections in the developing world. Herpes 1: 24-35.

28. Eis-hubinger AM, Nyankiye E, Bitoungui DM, Ndjomou J (2002) Prevalence of herpes simplex virus type 2 antibody in Cameroun. Sex Transm Dis 29: 637-642.

29. Saidi H Kapiga, Noel E Sam, Heejung Bang, Quanhong Ni, Trong T H Ao, et al. (2007) The role of herpes virus type 2 and other genital infections in the acquisition of HIV -1 among high risk women in Northern Tanzania. J Infect Dis 46: 631-642.

30. Van de Perre $P$, Segondy $M$, Foulongne $V$, Ouedraogo A, Konate I, et al. (2008) Herpes simplex virus and HIV-1: Deciphering viral synergy. Lancet Infect Dis 8: 490-497.

31. Rebbapragada A, Wachihi C, Pettengell C, Sunderji S, Huibner S, et al. (2007) Negative mucosal synergy between herpes simplex type 2 and HIV in the female genital tract. AIDS 21: 589-598.

32. Corey L, Wald A, Celum CL, Quinn TC (2004) The effects of HSV-2 on HIV-1 acquisition and transmission: A review of two overlapping epidemics. J Acquir Immune Defic Syndr 35: $435-445$.

33. Brown ZA, Selke S, Zeh J, Kopelman J, Maslow A, et al. (1997) The acquisition of herpes simplex virus during pregnancy. N Engl J Med 337: 509-515.

34. McClelland RS, Lavreys L, Katingima C, Overbaugh J, Chohan V, et al. (2005) Contribution of HIV-1 Infection to acquisition of sexually transmitted disease: 10-year prospective study. J Infect Dis 191: 333-338.

35. Alison C Roxby, Drake AL, Ongecha-Owuor F, Kiarie JN, Richardson B, et al. (2012) Effect of valacyclovir markers of disease progression in post-partum women co-infected with HIV-1 and herpes simplex virus 2. PloS One 7: e38622.

36. Wright PW, Hoesley CJ, Squires KE, Croom-Rivers A, Weiss HL, et al. (2003) A prospective study of genital herpes simplex virus type 2 infection in human immunodeficiency virus type 2 infection in HIV-1 seropositive women: Correlations with cd4 cell count and plasma HIV-1 RNA level .Clin infect Dis 36: 207-211.

37. Dipankar Biswas, Biswajyoti Borkakoty, Jagadish Mahanta, Kamini Walia, Lahari Saikia, et al. (2011) Seroprevalence and risk factors of herpes simplex virus type-2 infection among pregnant women in Northeast India. BMC Infect Dis 11: 325.

38. Gomes CM, Giraldo PC, Gomes Fde A, Amaral R, Passos MR, et al. (2007) Genital ulcers in women: Clinical microbiology \& histologic characteristics. Braz J Infect Dis 11: $254-260$ 